\title{
Fellow Column: Objective Measures of Neonatal Pain
}

Benjamin Shlomo, MD, Derek McCalla, MD

\section{Introduction:}

Pain is a recurring concern for pediatric physicians that is particularly complicated in the neonatal patient who cannot verbally articulate even the amount of pain.

Discussion: Per interviews with the nursing staff of both the PICU and wards, the Loma Linda University Children's Hospital measures pediatric pain in one of three ways, depending on patient competency: Older children are asked to self-rate their pain on the 1-10 scale, also known as a "Visual Analog Scale" (VAS). Verbal but less mature patients are shown the Wong-Baker (WB) faces (1) and asked to select the nearest representation of their pain. Research has shown that child Wong-Baker ratings correlate to their VAS ratings and that neither WB nor VAS ratings correlate to a Fear Scale, suggesting both measure pain rather than fear (2); Finally, the pain level of nonverbal children are judged by the nursing staff according to the FLACC scale (3). FLACC uses third-party observation of the Face (grimacing), Leg (position), Activity (level), Cry, and Consolability on a 0-2 scale for each of the five criteria. FLACC has been incorporated directly into the LLU Epic EMR flowsheets.

Third-party ratings of pain may be unreliable. For example, in one study of 63 emergency department patients from 4 to 7 years of age, self-reported ratings on a scale similar to WB (the Smiley Analog Scale) did not correlate with physicians' ratings of their pain and only very slightly correlated with parent's ratings of their children's pain (4).

It has been argued that the patient's sense of his or her pain should be "the primary source of information since it is more accurate than the observation of others" (5). However, in the field of psychology, self-report is often considered the least reliable form of data-gathering: "Although self-report measures are easy to obtain and inexpensive, they are notoriously inflated and inaccurate..." (6). "Why would the researcher trust what people say about themselves?" (7). Indeed, in studies of adults, the intensity of pain complained of often did not match the intensity of the pain stimulus delivered (8), and a quality improvement plan that routinely measured pain as "the 5th vital sign" did not appear to improve quality of pain management (9). A questionnaire of longterm elderly care nurses showed they were more likely to trust their physical exam findings of facial expressions of pain than patients' descriptions, and the more experienced the RN, the less they trusted self-reported pain (10).

Ironically, although self-report is considered unreliable, proposed objective modalities for measuring pain (including FLACC) are judged by how strongly they correlate to it. Then why bother examining or applying objective measures of pain? One advantage to objective measurement is to counterbalance biases that might influence physicians' subjective evaluations, such as towards race, gender, spoken language, etc. (11). Another purpose could be to distinguish genuine pain from faked pain, such as when a patient may have social rather than medical reasons for wanting to stay in the hospital (12). Alternatively, one could detect when a patient was masking the degree of suffering, such as in a child who believes they will go home faster if they lie about not being hurt (13). Finally, preverbal or nonverbal patients, including the entire neonatal population, cannot describe symptoms for the doctor, so objective pain measures would help guide therapy.

\section{"Alternatively, one could detect when} a patient was masking the degree of suffering, such as in a child who believes they will go home faster if they lie about not being hurt (46). Finally, preverbal or nonverbal patients, including the entire neonatal population, cannot describe symptoms for the doctor, so objective pain measures would help guide therapy."

Vital signs have traditionally been suggested as possible measurements of pain. In one study of 120 adult ICU patients, heart rate and respiratory rates increased, and $\mathrm{SpO} 2$ decreased in correlation with pain scores (by either VAS or "Behavioral Pain Scale" if unconscious) (14). Another study of almost 1.5 million children found heart rate and respiratory rates were higher in acute ER presentations than the upper normal standards of APLS and PALS. (15).

Acute pain leads to generalized sympathetic nerve activity, which raises BP. (16). Increased BP can cause a pain-relieving and possibly stress-relieving effect due to increased endorphin release (17). However, evidence shows that high BP reduces pain sensory thresholds $(18,19)$, making the detection of acute pain by BP changes in chronic hypertension more complicated than in normotensive patients.

Tachycardia is also frequently used as a sign of pain in many observational scales, but not all research confirms the relationship. In one study of acute pain in 10,617 adult ER visits, "heart rate and self-reported pain were correlated among whites, but the association was modest. ...Among blacks, there was no statistical difference in heart rate across all pain scores." (20).

Various modalities have been used to reverse-engineer neuroimaging patterns that correlate with pain, including fMRI, PET, NIRS (near-infrared spectroscopy), EEG, and MEG (magnetoencephalography). However, aside from radiation exposures, such imaging is typically too expensive and time-consuming for routine daily pain-monitoring (21). In the neonatal population, imaging would be further limited by the need to obtain sedation to keep the patient from moving too much for the scan.

Neuroendocrine hormones have been proposed as markers of pain (22), but studies have shown variable results. For example, procedural pain did not raise plasma cortisol levels or catecholamines in adult intensive care patients after cardiac surgery (23).

Salivary amylase has also been shown to increase with self-report with WB faces pain scale in children (24). However, again, research data has been mixed. Another study in Neonates showed no definite changes in salivary biomarkers (Salivary cortisol $(\mathrm{s} \mathrm{CgA})$ or salivary amylase (sAA)) detected before and after heel lancing (25).

"Facial expression is perhaps the biggest determinant and most 
consistent cue in judging pain in children...even above cry...Literature reviews report over 20 behavioral/observational scales, all of which essentially have some component of facial expression" (26).

Research interpreting facial expressions relies on the theory that such expressions have consistent meanings. Prior to the 1960s, most sociologists believed that human emotions were specific to individual cultures, which explained why some languages had words for unique emotions (for example, the Italian word for the specific pride at one's achievement "fiero") (27). Conversely, Charles Darwin wrote the first book on Evolutionary Psychology, The Expression of Emotions in Man and the Animals, arguing that emotional displays were innate and evolved as part of natural selection and shared among humans and other species (28). For instance, the expression of fear opens one's eyes to observe better while signaling to the pack that a predator is nearby, while the expression of disgust wrinkles the nose to limit the inhalation of toxic substances.

In 1963, a psychologist named Paul Ekman took photographs of Caucasian graduate students posing the emotional expressions as described by Darwin and demonstrated that naïve subjects universally identified the expressions consistently. But what if that were a function of cross-cultural sharing through travel or television? Ekman researched the Fore tribe of Papua New Guinea, a society that had almost no contact with the outside world, as well as no reflective surfaces or clean water, and therefore had never seen their own faces. The Fore, too, correctly identified-through a translator--the same images of Caucasians posing emotional facial expressions, demonstrating that facial signaling was universal among humans (29). Later research confirmed this finding, for instance, showing that congenitally blind winners and losers in Paralympic Judo exhibit the same expressions for pride and shame, respectively, as those sighted competitors in Olympic Judo (30).

The next step was developing an objective system for studying expressions. After 8 years of work, Ekman and Dr. Wallace Friesen published the Facial Action Coding System. The functional unit of FACS is an "Action Unit," a muscle group that contracts at different intensities, rated by suffixes of "a" ("trace") to "e" ("maximum") to alter a subject's expression. FACS itself makes no judgments about the meaning of the expressions observed (31). It takes a human approximately 100 hours to learn how to code photographs or videos into FACS units by visual changes alone; however, modern research now includes computer programs that auto-code video (32). FACS has since been adapted to the human infant (33) and various animal $(34,35)$ physiology.

Neonatal research using FACS has led to a variety of discoveries, for example, that newborns who have never tasted anything before still have distinct facial expressions for sweet, sour, and bitter tastes (36), but the most relevant research to this essay is the facial expression of Pain.

A study of 117 adults with chronic low back at a tertiary care clinic asked to pose for 6-second videos at baseline, on the exam, while hiding the effect of painful movement, and while posing pain showed that there was a universal facial expression of pain. The face of pain specifically consists of AU4 (eyebrow lowerer with vertical glabella wrinkling), AU6 (cheek raiser/crow's feet wrinkler), AU7 (eyelid tightener/squinting), A10 (upper lip raiser), AU25 (mouth opener), and AU43 (upper eyelid closer). Adults were able to produce all of those same action nits when faking/posing pain at statistically significant levels above baseline, whereas when hiding/masking/suppressing true pain, only AU25 (mouth opening) and AU43 (upper eyelid closing) appeared more often than baseline (37). Note that many studies include AU9 (the levator labii superioris alaeque nasi muscle strands) instead of or in ad- dition to the anatomically adjacent AU10 (levator labii superioris caput infraorbitalis muscle strands) (38); either AU is interchangeably part of the universal facial expression for disgust when symmetrical, and contempt when asymmetrical (39).

A sister study using the same dataset as (37) showed that judges were able to distinguish genuine pain faces from baseline expressions but, relative to genuine pain faces, attributed more pain to faked faces and less pain to suppressed ones." In judging the intensity of observed pain, judges' opinions correlated only with AU6 and AU43. In self-reporting of Pain intensity, the subjects' opinions correlated only with AU6. Warning of deception did not improve discrimination but led to a more conservative or nonempathic judging. "Facial information consistently was assigned greater weight" than verbal claims (40).

In another study of adult pain induced by electric shock, cold, pressure, and ischemia, researchers found that all 4 modalities produced the same universal facial expression of pain (38). Later investigations have shown the same expression for acute (41) as chronic pain. Similar findings confirming the same universal facial expression of pain was found in automated coding of 57 neonates during heelstick, with no differences by gender or ethnicity (42). Pain can have different intensities and different time courses, but it always looks the same unless the patient is suppressing or faking.
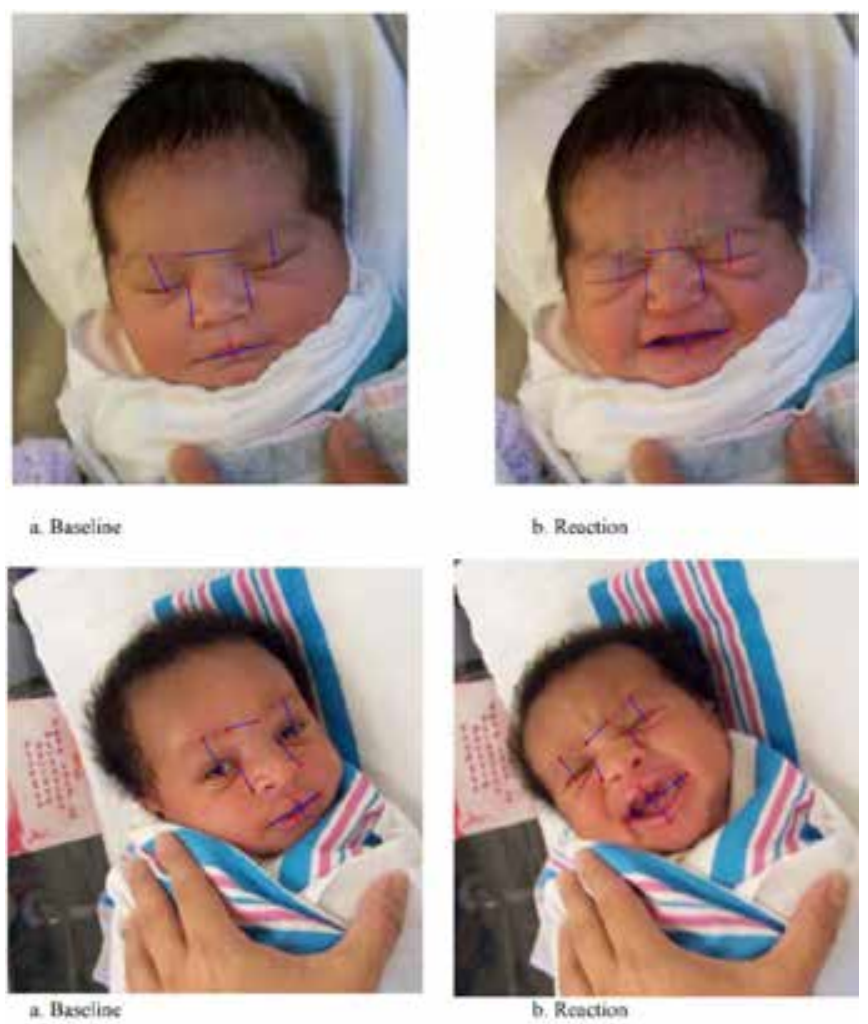

Fig. 1: An example of automated coding of the facial expression of pain. From Schiavenato, M. Evaluating Neonatal Facial Pain Expression: Is There A Primal Face Of Pain '" (2007). Electronic Theses and Dissertations, 2004-2019;3337:

htt.ps://stars.library.ucf.edu/etd/3337 (used with permission of the author)

"Faked expressions of pain in [8-12-year-old] children were found to show more frequent and more intense facial actions compared to their genuine pain expression...suppressed expressions, however, showed no differences from baseline ...Parents correctly identified the four conditions significantly more frequently than would be expected by chance. They were generally quite successful at detecting faked pain...children are capable of controlling their facial expressions of pain when instructed to do so. However, they are better able to hide their pain than to fake it" (40). Infant pain expressions show more consistent research outcomes than 
similar investigations of adult faces (43), "leading one to believe that exposure, experience, and normal human development may lead to modulation of the facial display." (42). Therefore, the suggestion is that using facial expressions to measure pain would be particularly reliable in neonates compared to older children because babies have not yet learned the social actions of hiding or faking their hurt.

Research involving FACS in pediatrics has shown a good correlation with other measures of pain. Facial coding of muscles of pain expression in infants post-surgery correlates with the nurse reports used to direct morphine administration (44). Computerautomated coding of ongoing pain in 5-17-year-old post-laparoscopic appendectomy patients' chronic pain demonstrated a higher correlation with child self-ratings (on a VAS-equivalent 0-10 scale) than with nurses' ratings and performed similarly to parent ratings. Automated coding performed similarly to nurses for pain induced by palpation. (45).

The physician's task is to synthesize the subjective and objective measures to make a clinical judgment about pain and its management. Facial expressions of pain correlate with self-reporting and require no special equipment other than direct observation. Comparing subjective pain to objective pain could help bridge the gap for patients and physicians when forming pain goals.

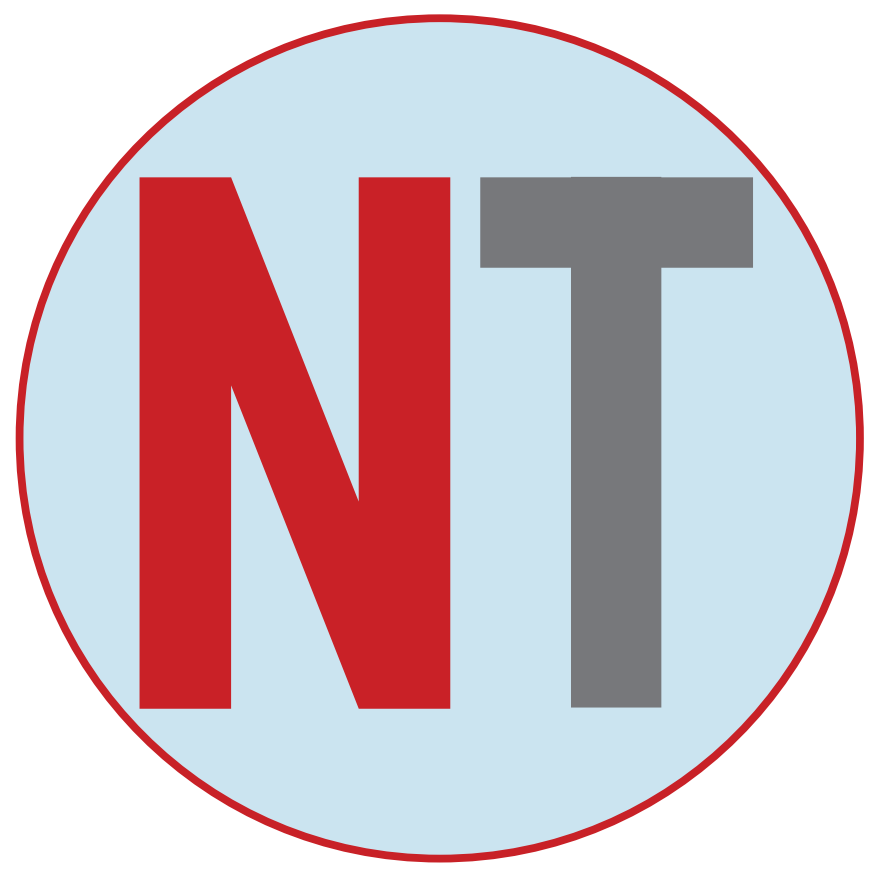

References:

1 Wong D, Baker C. Pain in children: Comparison of assessment scales. Pediatric Nursing. 1988;14(1):9-17.

2 Garra G, Singer AJ, Domingo A, Thode HC Jr. The WongBaker pain FACES scale measures pain, not fear. Pediatric Emergency Care. 2013 Jan;29(1):17-20. doi: 10.1097/ PEC.0b013e31827b2299. PMID: 23283256.

3 Merkel S, Voepel-Lewis T, Shayevitz JR, et al: The FLACC: A behavioural scale for scoring postoperative pain in young children. Pediatric nursing 1997;23:293-797.

4 Singer AJ, Gulla J and Thode HC Jr. Parents and practitioners are poor judges of young children's pain severity. Academic emergency medicine: official journal of the Society for Academic Emergency Medicine. 2002;9(6):609-612.

5 Joint Commission. Pain Assessment and Management: An Organizational Approach. Oakbrook Terrace: IL: Joint Commission on Accreditation of Healthcare Organizations. 2000;p13.

6 Smith AW, Gutierrez-Colina AM, Guilfoyle SM, Modi AC. Adherence and Self-Management in Pediatric Populations, Chapter 9 - Pediatric epilepsy. Academic Press. 2020; p207233. https://doi.org/10.1016/B978-0-12-816000-8.00009-8.

7 Robins R, Fraley C, Krueger R. Handbook of Research Methods in Personality Psychology. The Guilford Press. 2007; p228. ISBN 9781593851118.

8 Mader T, Blank F, Smithline H, Wolfe J. How reliable are pain scores? A pilot study of 20 healthy volunteers., Journal of Emergency Nursing. 2013;(29):322-325.

9 Mularski RA, White-Chu F, Overbay D, Miller L, Asch SM, Ganzini L. Measuring pain as the 5th vital sign does not improve quality of pain management. Journal of General Internal Medicine, 2006;21(6):607-612.

10 Katsma $D L$, Souza $C H$. Elderly pain assessment and pain management knowledge of long-term care nurses. Pain Management Nursing. 2000;1(3):88-95.

11 Ferguson WJ, Candib LM. Culture, language, and the doctor-patient relationship. Family Medicine. 2002;34(5):353361.

12 Mittenberg W, Patton C, Canyock EM, Condit, DC. Base rates of malingering and symptom exaggeration. Journal of Clinical and Experimental Neuropsychology. 2002;24(8):10941102.

13 Larochette AC, Chambers CT, Craig KD. Genuine, suppressed and faked facial expressions of pain in children. Pain. 2006;126(1-3):64-71.

14 Erden S, Demir N, Ugras GA, Arslan U, Arslan S. Vital signs: Valid indicators to assess pain in intensive care unit patients? An observational, descriptive study. Nursing \& Health Sciences. 2018 Dec;20(4):502-508. doi: 10.1111/nhs. 12543. Epub 2018 Jul 20. PMID: 30027620.

15 Bae W, Kim K, Lee B. Distribution of Pediatric Vital Signs in the Emergency Department: A Nationwide Study. Children (Basel). 2020 Aug 5;7(8):89. doi: 10.3390/children7080089.

NEONATOLOGY TODAY is interested in publishing manuscripts from Neonatologists, Fellows, NNPs and those involved in caring for neonates on case studies, research results, hospital news, meeting announcements, and other pertinent topics. Please submit your manuscript to: LomaLindaPublishingCompany@gmail.com 
PMID: 32764263; PMCID: PMC7465456.

16 Fagius J, Karhuvaara S, Sundlof G. The cold pressor test: effects on sympathetic nerve activity in human muscle and skin nerve fascicles. Acta Physiol Scand. 1989;137(3):325334.

17 Sheps DS, Bragdon EE, Gray TF III, et al. Relation between systemic hypertension and pain perception. American Journal of Cardiology. 1992;70(16):3F-5F.

18 Ghione S, Rosa C, Mezzasalma L, et al. Arterial hypertension is associated with hypalgesia in humans. Hypertension. 1988;12(5):491-497.

19 Ghione S. Hypertension-associated hypalgesia. Evidence in experimental animals and humans, pathophysiological mechanisms, and potential clinical consequences. Hypertension. 1996;28(3):494-504

20 Dayoub EJ, Jena AB. Does Pain Lead to Tachycardia? Revisiting the Association Between Self-reported Pain and Heart Rate in a National Sample of Urgent Emergency Department Visits. Mayo Clinic proceedings. 2015;90(8):11651166. $h$ ttps://doi.org/10.1016/j.mayocp.2015.06.007.

21 Morton DL, Sandhu JS, Jones AK. Brain imaging of pain: state of the art. Journal of pain research, 2016;(9):613-624. https://doi.org/10.2147/JPR.S60433.

22 Tennant $F$. The physiologic effects of pain on the endocrine system. Pain and Therapy. 2013;2(2):75-86. https://doi. org/10.1007/s40122-013-0015-x.

23 van Gulik L, Ahlers S, van Dijk M, Bruins P, Meima ME, de Rijke YB, Biemond-Moeniralam HS, Tibboel D, Knibbe $C A$. Procedural pain does not raise plasma levels of cortisol or catecholamines in adult intensive care patients after cardiac surgery. Anaesthesia and Intensive Care. 2016 Jan;44(1):52-6. doi: 10.1177/0310057X1604400109. PMID: 26673589.

24 Anggraeni H, Suharsini M, Indiarti I, Yumasdhika F. Correlation between wong-baker faces pain scale and salivary alpha-amylase level in children aged 6-11 years. International Journal of Applied Pharmaceutics. 2018;9(Special Issue 2): 133-134. https://doi.org/10.22159/ijap.2017.v9s2.34.

25 Shibata M, Kawai M, Matsukura T, Heike T, Okanoya K, Myowa-Yamakoshi M. Salivary biomarkers are not suitable for pain assessment in newborns. Early Human Development. $2013 \mathrm{Jul} ; 89(7): 503-6$. doi: 10.1016/j.earlhumdev.2013.03.006. Epub 2013 Apr 10. PMID: 23583069.

26 Schiavenato M. "Evaluating Neonatal Facial Pain Expression: Is There A Primal Face Of Pain?" (2007). Electronic Theses and Dissertations, 2004-2019; 3337:89. https:// stars.library.ucf.edu/etd/3337.

27 Ekman P. Emotions Revealed. New York: Henry Holt. 2003.

28 Darwin C. The Expression of the Emotions in Man and Animals. 1980 Ed. London: John Muray. p66. Available at http:// darwin-online.org.uk/content/frameset?itemID $=F 1142 \&$ view type $=$ text\&pageseq $=1$.

29 Ekman P. Universals and cultural differences in facial expressions of emotion. In J. Cole (Ed.), Nebraska Symposium on Motivation. 1971; (19):207-282. Lincoln: University of Nebraska Press.

30 Tracy JL, Matsumoto D. The spontaneous expression of pride and shame: Evidence for biologically innate nonverbal displays. Proceedings of the National Academy of Sciences of the United States of America. Aug 19 2008;33(105):1165560.
31 Ekman P, Friesen WV. The Facial Action Coding System. Palo Alto, CA: Consulting Psychologists Press. 1978.

32 Hamm J, Kohler CG, Gur RC, Verma R. Automated Facial Action Coding System for dynamic analysis of facial expressions in neuropsychiatric disorders. Journal of neuroscience methods. 2011;200(2):237-256. https://doi.org/10.1016/j. jneumeth.2011.06.023

33 Oster $\mathrm{H}$. Emotion in the infant's face: insights from the study of infants with facial anomalies. Annals of the New York Academy of Sciences. 2003;(1000):197-204.

34 Waller BM, Peirce K, Caeiro CC., Scheider L, Burrows AM, McCune S, Kaminski J. Paedomorphic facial expressions give dogs a selective advantage. PloS one. 2013;8(12):e82686. https://doi.org/10.1371/journal.pone.0082686.

35 Parr LA, Waller BM, Burrows AM, Gothard KM, Vick SJ. Brief communication: MaqFACS: A muscle-based facial movement coding system for the rhesus macaque. American Journal of Physical Anthropology. 2010;143(4):625-630. https://doi.org/10.1002/ajpa.21401

36 Rosenstein $D$ and Oster $H$. Differential facial responses to four basic tastes in newborns. Child Development. 1988 Dec;59(6):1555-68. PMID: 3208567.

37 Craig KD, Hyde S, Patrick CJ. Genuine, suppressed and faked facial behavior during exacerbation of chronic low back pain. Pain. 1991;(46):161-171.

38 Prkachin, KM. The consistency of facial expressions of pain: a comparison across modalities. Pain. 1992;(51):297-306.

39 Ekman, P, Friesen, WV. Unmasking the face: A guide to recognizing emotions from facial clues. Englewood Cliffs, $\mathrm{NJ}$ : Prentice-Hall. 1975:p114-128.

40 Poole, GD, Craig, KD. Judgments of genuine, suppressed, and faked facial expressions of pain. Journal of Personality and Social Psychology, 1992;63(5): p797-805. http://dx.doi. org/10.1037/0022-3514.63.5.797

41 Larochette AC, Chambers CT, Craig KD. Genuine, suppressed and faked facial expressions of pain in children. Pain. 2006 Dec 15;126(1-3):64-71. doi: 10.1016/j. pain.2006.06.013. Epub 2006 Jul 24. PMID: 16860478.

42 Schiavenato, M."Evaluating Neonatal Facial Pain Expression: Is There A Primal Face Of Pain?" (2007). Electronic Theses and Dissertations, 2004-2019;3337: https://stars. library.ucf.edu/etd/3337

43 Craig, KD, Prkachin, KM, Grunau, RE. The facial expression of pain. In D. C. Turk \& R. Melzack (Eds.), Handbook of pain assessment (2nd ed.). 2001. New York: The Guilford Press.

44 Peters JW1, Koot HM, Grunau RE, de Boer J, van Druenen MJ, Tibboel D, Duivenvoorden HJ. Neonatal Facial Coding System for assessing postoperative pain in infants: item reduction is valid and feasible. Clinical Journal of Pain. 2003;19(6): p353-63.

45 Sikka, K, Ahmed, AA, Diaz, D, Goodwin, MS, Craig, KD, Bartlett, MS, Huang, JS. Automated Assessment of Children's Postoperative Pain Using Computer Vision. Pediatrics. 2015;136(1), e124-e131. https://doi.org/10.1542/ peds.2015-0029

46 Larochette AC, Chambers CT, Craig KD. Genuine, suppressed and faked facial expressions of pain in children. Pain. 2006;126(1-3):64-71. 
Acknowledgment:

The authors would like to thank Dr. Matthew Fong in the Department of Pediatrics at Loma Linda University School of Medicine for his assistance in developing this topic and constructive feedback on this article's content.

Disclosure: The authors identify no conflict of interest

NT
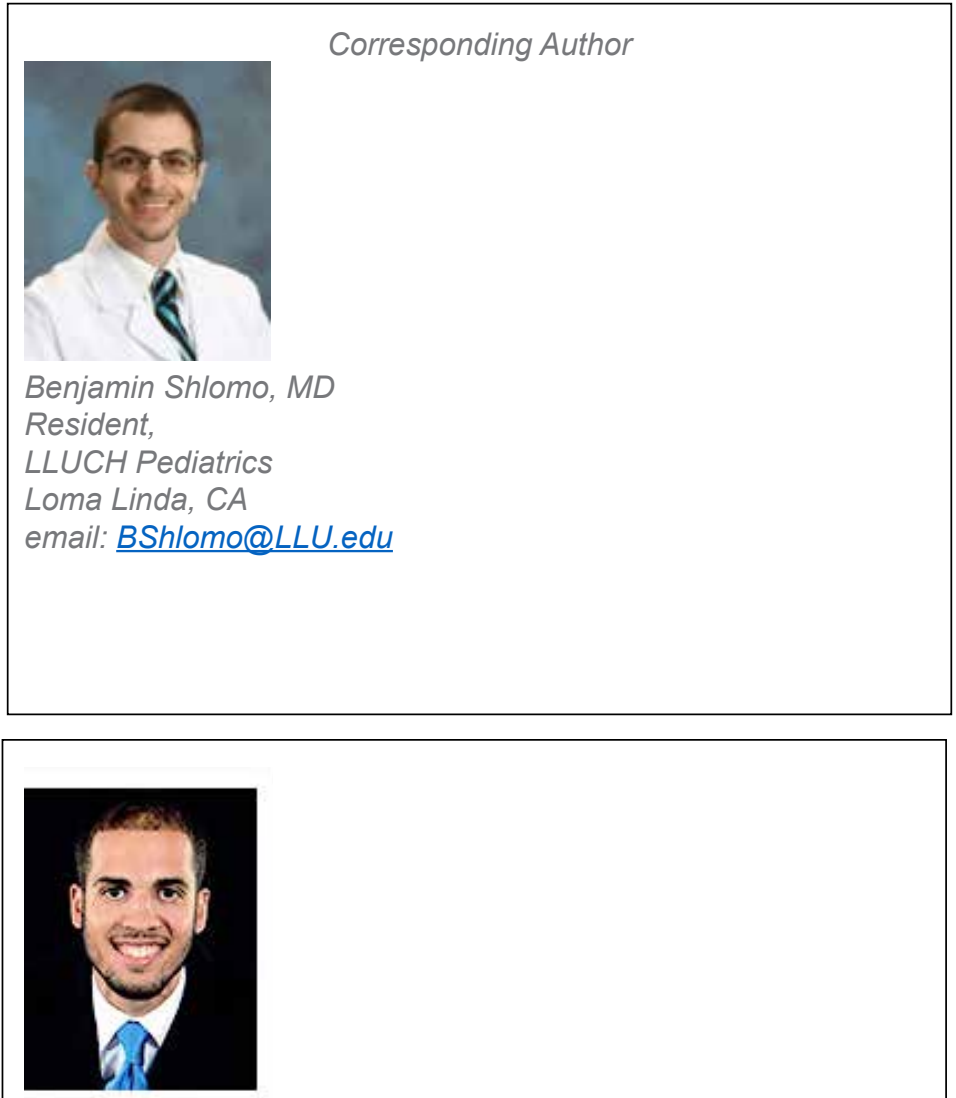

Derek McCalla, MD

Resident,

LLUCH Pediatrics

Loma Linda, CA

email: DMccalla@llu.edu
Fellow's Column is published monthly.

- Submission guidelines for "Fellow's Column":

- 2000 word limit not including references or title page. Exceptions will be made on a case by case basis

- $\quad$ QI/QA work, case studies, or a poster from a scientific meeting may be submitted.

- Submission should be from a resident, fellow, or NNP in training.

- Topics may include Perinatology, Neonatology, and Younger Pediatric patients.

- $\quad$ No more than 20 references.

- Please send your submissions to:

\section{Elba Fayard, MD}

Interim Fellowship Column Editor LomaLindaPublishingCompany@gmail.com

\section{Ootional Perinatal Association PERINATAL MENTAL HEALTH}

nationalperinatal.org/position

www.nationalperinatal.org/mental_health

\section{OFFER}

ANTICIPATORY

GUIDANCE

Families need to know

that women are

more likely to develop

depression and anxiety

during the first year

after childbirth than

at any other time in

their life.

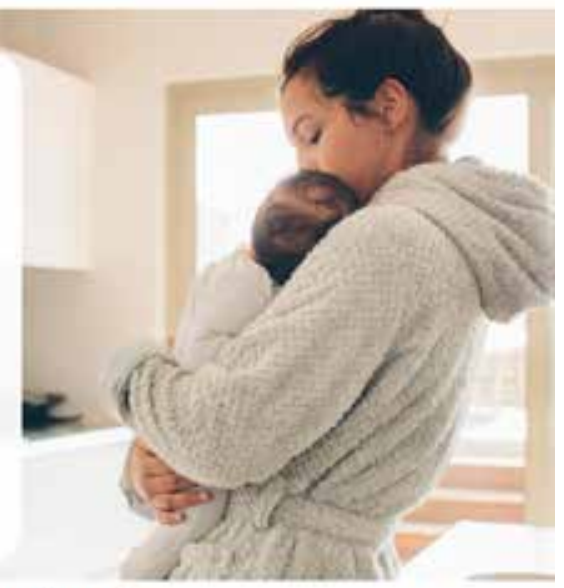

Educate. Advocate. Integrate.

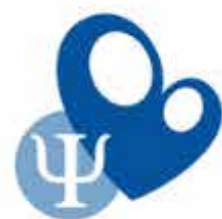

National Network of NICU Psychologists

Www.nationalperinatal.org/psychologists

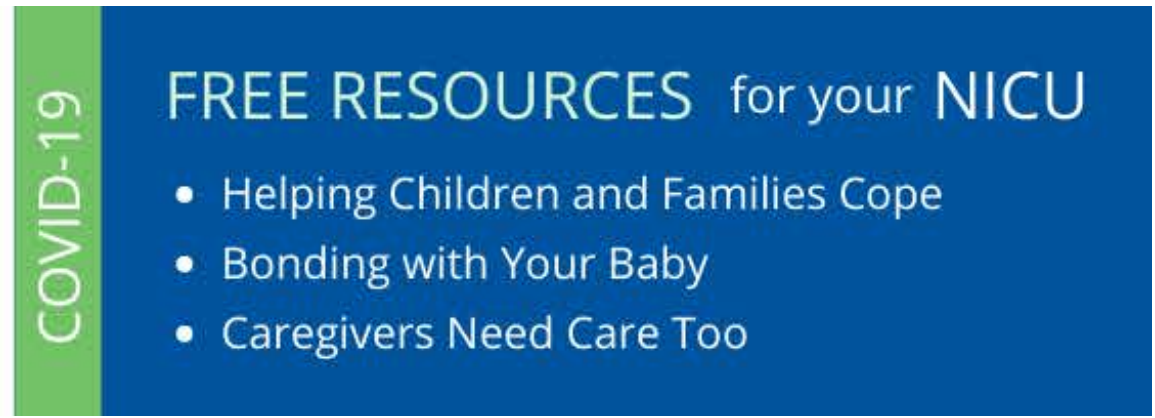

